\title{
archOnline@JCU
}

This is the Accepted Version of a paper published in the journal Childhood Education:

Carter, Margaret Anne, and Dasson, Merilyn (2017) What school leaders are doing to support a culture of character: an exploratory study with preschools in Singapore. Childhood Education, 93 (1). pp. 29-38.

http://dx.doi.org/10.1080/00094056.2017.1275234 


\title{
What School Leaders Are Doing to Support a Culture of Character. An Exploratory Study With
}

\section{Preschools in Singapore}

Margaret Anne Carter and Merilyn Dasson

Margaret Anne Carter is James Cook University Australia. Merilyn Dasson is Archdiocesan Commission for Catholic Schools Singapore.

\begin{abstract}
This article discusses an exploratory study, reporting the practices of five principals leading character development in early childhood centers in Singapore. Acknowledging that variations in leadership style, the pooled focus group findings show the common denominator is the principals' paradigm of authentic leadership informing a service orientated culture. Insights into the practices of these principals identify meaningful ways of building and sustaining a shared vision of respect, connectedness, cohesiveness, trust, positive morale, care and courtesy built on the principles of integrity, trust, hope, and love. Findings identify the contribution of five visionary principals working with character development in early education spaces in Singapore preschools.
\end{abstract}

The exploratory study discussed in this article is part of a three-year character in education project for Catholic preschools in Singapore (CPS) involving school-wide social conventions and character-ineducation practices (Carter \& Dasson, 2014). This article begins with an introduction to biological systems theory and the context for the study followed by a discussion on character development and leadership practices. Next, the methodology for the study is described and the narratives of five principals is presented and discussed. The article concludes with limitations of the study, suggestions for possible extensions, and practical implications for building school leaders common values and affirming school wide character development practices. 


\section{Bio-ecological System Theory}

In Bronfenbrenner's bio-ecological systems theory (Bronfrenbrenner \& Morris, 2006; Rosa \& Tudge, 2013), human development occurs within a series of embedded systems (microsystem, mesosystem, ecosystem, macrosystems, and chronosystem; see Figure 1). Emphasizing the role of nature and nurture, all systems influence and are influenced by the developing person over time. The microsystem is an immediate social and physical environment in which the person directly interacts with other people, influencing and being influenced by them. The connections in the microsystem, involves the changing interactions of the developing person with their immediate settings such as family, peers, educational settings, religious organizations and neighborhood environments. The interrelationship between two or more microsystems (mesosystem) influences, positively or negatively, what happens in other microsystems. For example, children exposed to permissive styles of discipline in their family (one microsystem) may experience challenges' with authoritative styles of management in schools (a second microsystem).

Likewise children can be influenced by settings that they do not directly experience but which still influences their development (exosystem). For example, children can be affected by governmental directives on education system curricula. The macrosystem is the cultural context within which all systems are embedded. This system encompasses shared cultural understandings, beliefs, values and expectations that influence the developing child. How does living in an individualistic or collectivist culture influence the values of the person? Changes or constancy that occur over the life course, in people and in environments, effects the developing child (chronosystem). For example terrorism may result in global turmoil, migration, erosion of values, changes in family structure, intolerance of diversity as well as deployment of government monies from education into counter terrorism activities.

Through early childhood children engage in developmental tasks including sensory/perceptual motor functions, interaction and language development, foundations of psychosocial development, attachment, gender identification, social cognition and early moral development. Secure attachments and reciprocal interactions with nurturing adults during this time increases children's sense of 
security, encourages positive relationships with others and influences early personality development. Through reciprocal interactions across a series of environmental systems children learn about themselves and others, expressing feelings and learning culturally appropriate prosocial behaviours essential for peace and harmony.

People and places in children's microsystem, mesoststem and exosystem are instrumental in forming beliefs about what it means to be a good person and "the eventual internalization of moral standards" (Newman \& Newman, 2015, p. 217). The cultural context of how people ought to lead their lives and what children need to be taught to function in society is affected by the marcosystem, wherein the microsystem, mesosystem and exosystem is embedded. Changes in environmental systems occur over time, are patterned over a person's lifetime and have an effect on the person.

Character education is one such development that occurs within interlocking systems, functioning in particular microsystems linked through mesosystems, entrenched in the exostystem and the culture that helps shape the marcosystem, all occurring in the person or environment over time. Character traits grow and mature over time as children interact with interlocking systems, functioning in microsystems linked through mesosystems, entrenched in the exosystem and the customs and culture of the help shape the marcosystem.

Insert Figure 1 here

Schools have cultures reflective of their ethos, vision/mission, systems, processes, and interactions. Through engagement and experience with their school's philosophical beliefs, educators, children, and families come to identify and comprehend their school's culture.

Culture is the basis on which the day-to-day life at school is built. . . Culture is deeply embedded in the school's history: beliefs, values, choices made, traditions kept. The school ethos is the result of this; the ambience that is felt as a result of its cultural history; past, present and ever changing. (Solvason, 2005, pp. 85-86) 
Children come to school with diverse knowledge, understanding, experiences, paradigms , and personalities. They are natural learners, gradually accumulating knowledge about the school's ethos and culture; they are competent and capable beings, who have repeated opportunities to learn human rights and cultural and humanitarian values. It is these learnings that foster character development and moral reasoning.

\section{Character Development}

Rudolf Dreikurs (1897-1972), an educator and psychiatrist, reasoned that the core purpose of human behaviour is acceptance and belonging with others in social contexts. He theorized that peoples' misbehaviours are directed toward successful interpersonal relationships, and are purposefully directed toward the attainment of four goals: attention, power, revenge, and incompetence. The role of adults is to construct an appropriate environment that supports children develop a sense of purpose as they learn the values of living and working together "in a spirit of sharing and collaboration" (Baligadoo, 2014, p. 432).

Values are guiding principles, standards of behavior by which persons live their lives. They support individuals in developing positive moral traits such as respect, kindness, care, compassion, responsibility, fairness, equality, and citizenship. Children's family, peers, school, neighborhoods, and societal views shape their values and attitudes. This development is influenced by ethics orientated interactions within and across nested environmental systems. As children engage with others across environmental systems over time, they learn the purpose, meaning, and application of values, while deciding for themselves what values to embrace.

As young children strive to define their own values, adults "have an obligation to be consistent models who exhibit the positive principles of caring for each other" (Henderson \& Thompson, 2011, p. 9). Through this process, children learn the power that values have in influencing the rest of their lives (Gordon \& Green, 2008). Sim and Low (2012) highlight the fundamental role virtues (human qualities such as wisdom, honesty, self-discipline) have in character formation, maintaining that "what constitutes good character defines the virtues we possess" (p. 383). 
Character development (alternatively, morals education, values education, civic education) holds that there are universal values that positively foster the development of good character. Researchers (Berkowitz, 2011; Berkowitz \& Bier, 2005, 2007) define character as the complex set of psychological characteristics (e.g., compassion, empathy, moral reasoning) that influence and empower an individual to "to function as a competent moral agent, that is, to do 'good' in the world" (Berkowitz, 2011, p. 153). Writing about values as the foundation of character development, Lickona's (1996) identified "the classic ethical tests of reversibility (Would you want to be treated that way?), and universalizability (Would you want all people to act this way in a similar situation?)" (p. 95), as the moral compass guiding children's thinking.

Principals as instructional leaders, modeling values-based leadership, are intent on developing a shared sense of social consciousness among community members (Zhu, Riggo, Avoilio, \& Sosik, 2011). "Schools are a repository of societal cultures which the leadership attempts to weave into a cohesive tapestry of educational vision and commitment, and this, in turn, becomes the organizational culture" (Hill, 2014, p. 175). The principal, as change agent, sets the direction of the school climate and ethos (conventions, mission, and vision) (Leithwood, 2010), promoting schoolwide positive procedures of behavior toward others. These procedures entail the teaching of social norms essential for peace and productivity, with repeated opportunities to practice prosocial behaviours that grow and develop children's self-regulation and social competence. As Kohn (1996) observes, "To help students become ethical people, as opposed to people who merely do what they are told, we cannot merely tell them what to do. We have to help them figure out-for themselves and with each other-how one ought to act" (p. 37).

A search of the literature indicates that despite no single approach to character development being reported, the 11 principles of effective character education articulate a framework for sustainable practices in school settings (Anderson, 2000; Berkowitz \& Bier, 2005, 2007; Character.org, 2014; Lewis, Hays, \& Robinson, 2011; Lickona, 1996; Lickona, Schaps, Lewis, \& Character Education Partnership, 2007; Sojourner, 2014).What is central with these ideologies are environments characterized by visible, credible influential leaders who desire to make a positive difference in the life of others (Table 1). They behave with respect, trust, openness, compassion, and collaboration. 


\section{Authentic Leadership}

Leaders in these spaces connect with others as they engage in networks of interconnected ecological systems. These interactions influence and are influenced by their mores as they

act in accordance with deep personal values and convictions, to build credibility and win the respect and trust of followers by encouraging diverse viewpoints and building networks of collaborative relationships with followers, and thereby lead in a manner that followers recognize as authentic. (Avolio, Gardner, Walumbwa, Luthans, \& May, 2004, p. 806)

Building on researchers conceptualization of authentic leaders (Avolio, Gardner, Walumbwa, Luthans, \& May 2004; May, Chan, Hodges, \& Avolio 2003), Shamir and Eilams' (2005) characteristics of effective leaders resonate here. Authentic leaders function from a value-based compass, transparent in action and deed (pp. 386-397). They regard themselves as social equals, esteeming different roles, responsibilities and jurisdictions, while working equitably with others. As Hester (1995) explains,

Life means equality, so that some do not grow at the expense of others. Every group and every person has value, and some persons live them more closely than others. Some people will live one value and one belief more strongly than another value or belief, and some will realize a cluster of values in their daily lives to a degree others cannot reach. (p. 41)

\section{Context}

Singapore is a regional education hub and global leader in the Asia Pacific region. It is a culturally diverse and technologically advanced small island nation with Singapore citizens and permanent residents (CMIO) - Chinese ( 43.3\%), Malay ( 13.3\%), Indian ( 9.1\%), and Others (3.3\%) (Yearbook of Statistics, Singapore, 2015) - living amicably with foreigners. Numerous religious groups (Buddhists, Muslims, Christians, Taoists, Hindus) live side-by-side, epitomizing religious harmony. 
While mother tongue language is assigned to Chinese, Mala,y and Indians, English is the language of government and instruction.

A growing body of research identifies Singapore with Confucian ethics such as deference to authority and filial piety, being combined with democratic doctrines including autonomy and individual liberty (Carter, Frewin, \& Chunn, 2014). National values are integral to Singapore's robust economy, high standard of living, and strict social controls. In Singapore, there is a ministerial directive that citizenship and character education (CEC) form an integral part of the future orientated service orientated global economy (Ministry of Education, Singapore, 2012a). This directive is regarded as central to an increasingly accountable, interconnected and multicultural market driven world. While conceding this reality it is important to acknowledge the Prime Minster of Singapore, Lee Hsien Loong, emphasis on the importance of play in childhood: "It's good for young children to play, and to learn through play" (Toh, Chia, \& Lua, 2012, A7). The adult seldom realizes that the ability to play with ideas in an abstract, thoughtful manner has been made possible by the active manner of exploration found in young childhood.

Insert: Table 1: Effective Principles of Character Education

In 2011, Mr Heng Swee Keat, Minister of Education, Singapore, looked to schools to "develop basic values of care, community and social responsibility, and social and moral dispositions, such as good neighbourliness and volunteering" (Sim \& Low, 2012, p. 388). Promoting an environmental systems approach to character building, Mr. Keat affirmed a shared set of national values integrated across nested systems including school, family, neighbour, workplace, government, and society. He advocated character development as the mission and vision of Singapore schools.

We must put values and character development at the core of our education system. ... Character development is about developing social emotional competencies, and the habits and inner disposition based on sound Values to act in a consistent way. Personal Values such as grit, determination and resilience enable the individual to realise his or her potential, and develop 
'performance character'. Moral Values enable the individuals to develop 'moral character. (Mr Heng Swee Keat, Singapore Minister of Education, Opening Address, Work Plan Seminar, 2011)

Aligning core values (respect, responsibility, resilience, care, and harmony), social emotional competencies (SEL), and critical literacy, global awareness, and cross-cultural skills (Ministry of Education, 2012a), the CEC curriculum is evidence of this ministerial commitment. While preschool and upper level schools have different program to bring forward values and character development in schools, the "Nurturing Early Learners - A Curriculum Framework for Kindergartens in Singapore" (NEL Framework), endorses the Ministry of Education (MOE) desired moral thinking and learning outcomes for every child in Singapore, to set the direction for working together in preschool spaces (children age 4 to 6$)$ :

A confident person who has a strong sense of right and wrong, is adaptable and resilient, knows himself, is discerning in judgement, thinks independently and critically, and communicates effectively.

A self-directed learner who takes responsibility for his own learning, who questions, reflects and perseveres in the pursuit of learning.

An active contributor who is able to work effectively in teams, exercises initiative, takes calculated risks, is innovative and strives for excellence.

A concerned citizen who is rooted in Singapore, has a strong civic consciousness, is informed, and takes an active role in bettering the lives of others around him. (Ministry of Education, 2012b, p. 7)

These governments led learning outcomes integrate with set "learning dispositions (perseverance, reflectiveness, appreciation, and inventiveness, sense of wonder and curiosity, and engagement)" (Ministry of Education, 2013, p. 6), to inform character development decision-making processes in Singapore preschools. As Sim and Low (2012) concludes, "Education is as much about building 
character as it is about equipping students with specific knowledge and skills necessary for the twenty first century" (p. 382).

With no prescribed approaches or processes espoused, principals are expected to design and lead character building instruction in their schools. Hence the researchers were curious to discern the role of principals in character development practices in schools. How do principals attend to and embrace their values while respecting others' values? How do values impact and define the many facets of character development practices? How do values emerge in their relationships with educators, children and families? Do principals monitor the impact their values have on character development practices in their schools?

\section{Methodology}

Research Question

The research reported in this paper is part of a three-year action research project involving the purposeful integration of character development in Catholic (Singapore) preschools (Carter, 2015; Carter \& Dasson, 2014; Carter, Dasson, \& Kanakis, 2016). The researchers were inquisitive to learn about the role of the principal in character development practices in their schools.

\section{Data Collection}

The ethical guidelines of the university and the employing authority were followed with approval for the research to proceed prior to the commencement of the data collection. Thematic analytic was the procedure the researchers followed to explore participants' narratives in a focused and transparent way.

Data were gathered through a focus group. A specific type of group interview, the focus group was considered an effective, economical and efficient means of gathering a thick description of the phenomenon in a short period of time. The focus group was designed to contextualize principals' contributions to a culture of character in CSPs. The project officer sent an email invitation to principals whose schools were part of the larger character-in- education project, inviting their anonymous and confidential participation in the focus group, scheduled on the final weekend prior to 
commencement of the school year. The focus group, facilitated by the first author, was conducted in English, and was one hour thirty minutes in duration. It was audio-recorded and the discussion was transcribed. To help maintain trustworthiness of the data, participants were given copies of the transcript to review and verify, and to add additional commentaries if appropriate. Quotes were used to illustrate the findings, provide the reader with a thick description of the phenomena under consideration.

\section{Data Analysis}

The coded responses from participants underwent a comparative analysis to generate themes. Braun and Clarke's (2006) systematic thematic analysis framework was used to code and categorize themes and subthemes: transcribing data, generating initial coding, examining data for emergent themes, searching for themes, reviewing themes, naming and defining themes, writing report (p. 96). An audit trail was maintained to help safeguard the analysis process, ensuring it was methodologically and theoretically sound. A thematic map was generated, providing a consistent interpretation of the data set. Relevant quotes were extracted from the data to show the thematic analysis of participants' reality.

\section{Participants}

The project officer sent an email invitation to principals whose schools were part of the larger character-in-education project, inviting their participation in the focus group, scheduled on the final weekend prior to commencement of the school year. All were Singaporean nationality, and all were female. The preschools ranged in total student enrolments from 72 to 309 and total staff members from 10 to 16.

\section{Findings}

This study was designed to identify what school leaders in CSP are doing to support a culture of character. Five principals participated in the focus group with an average age of 45.6 years $(\mathrm{SD}=6.66$, range $=40-55)$. The participants had been working in CPS for an average of 16.5 years $(S D=11.17$, 
range $=.5-32)$ and had been working at their current preschool for an average of 6.3 years $(\mathrm{SD}=7.09$, range $=.5-18)$.

The principals' narratives provide confirmation of actions that "reinforce and represent school cultures" (Solvason, 2005, p. 92). They provide rich descriptions of an accepting and welcoming culture grounded in faith, hope, love, respect, and compassion. These narratives depicted the positive influence of principals in recognizing character development as significant in the life of children's schooling. Themes were multidimensional including principal as lead manager, principal as coaching teacher, and principal as discerning monitor. While themes encompassing the practices and procedures of five principals are described separately, they are not mutually exclusive. Individual responses are identified as $\mathrm{P}$ (Principal) 1-5.

Theme A: Principal as Lead Manager

A recurring theme in the focus group was the changing values of children's experiences in the 21st century. With children today being confronted by senseless violence and injustice in our service driven economy, principals acknowledge their role as discerning leader, intervening wisely in the lives of children, teachers and families.

We are all facing the same problems like listening and taking turns in everything. For my centre, the younger children like the nursery or the two and a half years old, when they came in they are so-called very individualistic still. So it's like this. They don't really know how to take this and everything, so our teachers they try to incorporate in the daily routines and everything. (P3)

Parents entrust their child/children to the school, which sequentially, entrusts the child/children to the teacher. Following the enrolment, the principal delegates the task of schooling to a class, year level or teacher.

The school must give a warm and loving environment for any child and you are one of those who give that when the parents are not around. So it's the idea to let the teacher know where our place is. It's not just 
simply to teach, but to give that love in order to give that warm, that comfort, you know, that peace to a child that comes here so that when the child experience that school is a lovely place to be. (P3)

As engaging professionals' focus group participants are responsive to changing times, being strategic and reflective with systems, practices and processes. An understanding of and commitment to the ethos and culture of the school is critical as principals engage in collective conversations about the values aligned with the school's vision/mission.

In recent years doing conversation, the teachers have discovered that children are coming in lacking ... in social skills and we know that if there is no social skills, academic learning won't go in that because they won't have the heart ready to learn. ... I constantly remind the teachers that one of the vision mission in our school is the moral fibre of the child. (P1)

Confident in their leadership style, focus group participants create a shared vision of expectations for all in their school to live by. They are expectant leaders who along with staff, children and families, build a community of learners in which all grow, develop and succeed, peacefully and productively.

I think our stand is we share this value and we reinforce all these behaviours, things, and the message has been set out to the parents as well. (P1)

As knowledgeable leaders, focus group participants operate as non-coercive system thinkers, respecting the worth, dignity and uniqueness of each individual. Building working relationships based on trust, they are consistent in words and deeds with values and beliefs.

We have to be very consistent. So even the N1 and 2 group we do that too, because they have to be learned. .

.. They don't have a previous of experience, so everything they do, let them talk about it, think about it.

Even certain thing we discuss in front of the whole group, some we just individually. (P2) 
Promoting a culture of shared responsibilities focus group participants encourage staff to support one another in teaching children the social conventions.

We should not feel offended or we should not feel threatened if another teacher were to come and help us, you know, work on the social skill of that child. That means if I find that your child is not behaving anywhere and you are not there, it is okay for me to say, "What you did was not right. You shouldn't be doing this." And I always make it a point that I will do that when I see them, you know, not doing what they should be doing around the school, in the toilet, in the eating area, all this. So that what built the culture for the school. (P4)

Focus group participants are credible, aligning their character development practices with the school mission. They lead by example, exercising influence as they model the behaviours they want staff and students to display. Through this process, they are creating environments of empowerment engaging with others on a journey of learning.

As leaders, we should be the one to start it and we should be the one to show it to our teachers as role models ... every teacher has a share in that child. Every teacher should invest in that child. (P4) Acknowledgement is very important, because it will bring out the best to the child. (P2)

Open to others' contributions, focus group participants professionally engage with home, articulating and promoting expectations, commitment and expertise that foster values living learning.

Some parents really built the character of their children and I also want to know what is that formula, what do they do that I can use that in the school with the children, with the other children, so there is that familiarity as well for children. "My Daddy does that. My Mummy says that." . . At the end of the day, parents are the first teachers. (P4)

Theme B: Principal as Coaching Teacher 
Focus group participants regarded themselves as coaching teachers, purposely supporting teachers and children to achieve their person bests. They talked about networks of relationship, leading and managing an inclusive, socially sustainable school culture. The mantra of quality supports paralleling quality outcomes is emphasized as teaching rather than telling is the modus operandi.

I constantly remind the teachers that one of the vision mission in our school is the moral fibre of the child.

That is what we have in this school. (P4)

Teach the children the rules ... teach it explicitly. So the teaching is very important and during the morning gathering we can use the time to teach. (P5)

It's conscious, it's intentional. ... At the end of the year there's a summary as to how do you feel, what did you do, was it a success, why wasn't it not, which are the area you have difficult with, and things like that.

Focus group participants are effective communicators, cultivating an ethos where the enactment, celebration and teaching of character development is transparent. They build nurturing relationships working with staff, children and families to respect the dignity of each other.

I will get the teachers to share. I will say "Teacher so and so will share with you know ... and then I will support it by saying that." As a school this is the culture that we are in" and I come in with the theory part.

Focus group participants reported their commitment to identifying development, monitoring, reflecting and assessing social convention learnings. Accepting that teachers are always in a state of becoming, principals support them as they progress from novice to established practitioners.

When somebody is coming up with good ideas, somebody is doing some special work or the child has been very polite to the friend, we always acknowledge, "Oh, you have done a good job, you say thank you, you know, you say something so nice." We use the wise word. So if the child is not doing that good you say, 
"Oh do you think is that kind to your friend? Do you think it's safe to your body?" We always let them think about and reflect on their own. (P2)

Focus group participants identified that classroom environments and educator instructions may need to be changed or modified so all children are successful. This is an area necessitating repeated consideration and professional development.

There was this day I saw this child crying in a pitiful state, you know, I saw her like begging the teacher to let her come back to class and the teacher refuse because she kept saying, "I told you many, many times. You don't want to listen. You don't want to listen. You always never listen." So I just take in the scene as it is but after school or whatever when there was a quiet time, I will always approach the staff and say that, you know, "I would like to talk about what happened just now." So again, I let the staff tell me what happened and I share with her my point of view. I say, "From where I'm standing, from how I see, this is what I see the child as a traumatic experience." (P3) It's the same language, same thing throughout the whole school and home. (P1)

This process is similar to the medieval concept of Patrons and Masters, with "the Patron seeking out Masters-craftsmen, artists-and sponsoring them in their work or commissioned work of the community" (McArdle, 2002, AD7.18). Being values driven, they employ proactive such as, "I will," rather than reactive language "I cannot." They work with others building personal and professional capacities in values added learning activities.

Every term in our theme we will discuss as to what is the character portion, the variable that we want the children, you know, that we want to teach the children, so all will agree on one particular or two particular areas, and then the nursery, the K1 and K2s, they were the one who shared with me this year how they want to go about it. I said, "What are the different strategies that you will use to bring this up?" so they will have the plan in their level. This is how we carry it out this year. (P3)

Mistaken behaviours are viewed as platforms for teaching and learning. 
I have observed that the teacher actually talk to the child. When the child misbehave they will do this, "Come," then lower themselves and look eye to eye and they just talk to the child, see what's going on, what do you think and everything. And the other teacher will take the whole class, because if not, the other children will be running around and misbehaving and then accident happen. (P1)

Servant leadership practices are followed as focus group participants proactively exercise influence, promoting team work, celebrating everyone's achievements, valuing self-worth, growth, and development and success. Understanding the importance of teaching and scaffolding learning, they remain hopeful in their outlook as they coach educators to achieve desired outcomes. Focus group participants are decisive in action, balancing professional knowledge and reflection with strategic action. Principals lead educators and educators lead children in building their knowledge, skills and competencies of living and learning together respectfully, productively and harmoniously.

How can we prevent this incident happen again? So what can we do as a classroom basis? So the other teachers will talk about it and the children will contribute the ideas and suggestion to improve it. That's what we do with my partner. So I'm a Chinese teacher, so sure talk it in English and now I will do it in Mandarin, so the children are free to explain in their comfortable language. (P2) Everybody will take turns to come out and share about what they did. Some of them, "Today I use the listening ears and my focus eyes" and then some of them they say they maybe misbehave in certain area but we value the good point is they say they have the hand, they say they have the listening ears, you know, gentle, those kind of things. (P1)

Far from complacent, focus group participants recognize the Catholic education system level support while looking forward to next moves.

I really like what ACCS has for us, what the rules are, what it is not, because it is important to emphasise what it looks like, you know, what the behaviour looks like and what we do not we can use the time to teach the children the rules. I think the next thing that is important is the integration of the use of these rules in 
the classroom. The constant use of it in the classroom, the teachers and lastly the entire school culture.

That's where the teacher's model and the teachers talk about the rules. Everybody shares a common language. (P5)

Theme C: Principal as Discerning Monitor

Focus group participants are thoughtful observers and influential collaborators who know, monitor, and appreciate the skills and effort of their staff and students and the results they produce.

I have observed that the teacher actually talk to the child. (P1)

The good thing is the group of teachers that I have, they would take time to really incorporate this turn taking, saying thank you, teaching the children about all these social skills. (P3)

Character development practices are woven across curricula domains rather than restricted to single lessons or programs and disconnected to the school's mission. Examples of these practices include acts of generosity, storytelling, bilingual social problem solving, and school-wide assemblies.

We will take a story every day; we'll talk about it. The older classes will do a discussion. We ask the children, what if this thing happen in the class and some of the kids not happy. (P2)

Respectful persuasion rather than coercion shape school structures, guiding the formation of socially relevant identities. As Shamir and Eilam (2005) described, these focus group participants "hold their values to be true not because these values are socially or politically appropriate, but because they have experienced them to be true" (p. 397). They operate from positions of influence, wisely setting minimum level behaviours for working and learning peacefully and effectively together.

The boundaries for the child are extremely important because they will test the boundaries and you need to lay it out very specifically what these boundaries are, so they test you one time, this happens, test a second time, this happens. (P5) 


\section{Discussion}

Educating for character was the transformational mindset principals pondered, moving their school from a state of being to a state of becoming. In this study, the quantum leap discussed was the role principals' played connecting "individual and collective action by exercising power through people not over them" (Minckler, 2014, p. 660). Several of the leadership practices discussed in the focus group have some alignment with the guiding principles of character education (Table 1):

trustworthiness, trust, communication, teamwork, enablement, and alignment. Additional research is essential to substantiate the effectiveness and efficiency of this alignment.

Our findings indicated that principals' are driven by a constructive discontent to enact effective practices in character development in their schools. They remain optimistic as they develop a sense of "what is right and fair" (Avolio et al., 2004, p. 807), intentionally modeling the principles, beliefs and values they want others in the school to display. Beginning with the end in mind they are interested in each educator, child and family, demonstrating love, acceptance, and security.

As instructional leaders' principals intervene purposely in the lives of staff, students, and families. They encourage peaceful and constructive ways of working together, acting in ways they expect others to behave. They articulate core values (e.g., respect, love, compassion, teamwork), promote shared practices, observe educators and children in action, and provide encouragement and constructive feedback. They assess growth and recognize progress, monitoring and evaluating the alignment of values-based learning with the mission of character development. This mindset

subscribes to Confucian teaching: Give a man a fish, feed home for a day. Teach a man to fish, feed for a lifetime.

Being goal oriented principals are aware of the significant role of the teacher, reinforcing positive attitudes and complimenting what they are doing, by adding value and providing organizational support. They foster positive self-development for educators and children. They are proactive in their building nurturing relationships, endorsing and cultivating shared humanitarian values within their school communities. As Patrons they engage with staff, children and families intentionally creating a space for the Masters to work, develop and grow (McArdle, 2002; McArdle \& Carter, 2009). They 
build a sense of belonging, encouraging inclusion and discouraging criticism. They lead by example, wanting to make a significant difference professionally and personally, distributing leadership with others while also exercising leadership.

Principals' narratives identify a genuine interest, "a vision for those in service that teaches others to serve while awakening this same vision in other members of the organization" (Banke, Maldonado, \& Lacey, 2012, p. 236). They demonstrate and value individual differences building trust as they help educators' evaluate their own strengths. Expressing confidence in educators and children's' ability to succeed in character development, they provide opportunities for peer recognition and for educators to work together. They are conscious of compatibility and incompatibility with the vision of character building and are willing to make adjustments and provide support as necessary.

Creating a culture committed to the mission of character building, principals work with others on paradigms and processes. Getting results is important but how they get results matters. Using a distributive leadership style, principals built commitment among staff, children and families creating a common vision of expectations, shaping systems, processes and strategies as they work with staff and children to achieve the desired end. As Huber (2004) so persuasively specified, "They try to actively influence the culture of the school so that it allows and stimulates more cooperation, coherence and more independent learning and working" (p. 673).

Many principals adopt a social learning lens to support social connectedness and the democratic values of shared responsibility and social equality in the process of building values centered learning communities. Through this process they aspire to be non-coercive, genuine and accountable, leadmanaging school communities where humanitarian values are promoted. Research examining teachers' pedagogy is desirable to provide detail to the depth and breadth of character development practices "enmeshed across all curricula" (Wilhelm \& Firmin, 2008, p. 184).

Effective communication based on trust and trustworthiness is central in shaping what Hill (2014) refers to as "a strong widely supported school culture which enables the staff to have a common conceptual framework aligned with the leader's vision" (p. 184). Akin to the writing of McArdle and Carter (2009), principals proactively observe and monitor their communication, committed to 
ensuring they are exercising values-related influence as they work side-by-side teachers, children, and families.

\section{Limitations, Future Research Directions, and Practical Implications}

The results of this exploratory study need to be interpreted with caution due to the nature and size of the sample. Nevertheless, findings may be transferable to other settings as determined by the reader. Building on the findings in this study, the researchers are interested to study the leadership of principals in secular preschools in Singapore in supporting a culture of character development in their schools. Future research on the alignment of the character development leadership narratives with the school mission and vision would be meaningful. The development of authentic leadership and social identities is worthy of investigation, as is the developmental process of becoming influential leaders of character development. Examining the cultural responsiveness of character based practices is an important element of future research, as is mapping the cultural responsiveness and cultural intelligence of effective leaders. Using systems theory as the lens to explore how principals construct and build their character development knowledge is worthy of attention.

Principal as Lead Manager

Principals as lead managers build a shared vision/values mission statement of character development that is accountable, credible, communicable, and non-coercive (McArdle, 2002). The vision-making process captures three timeframes: past, present and future. It is purposeful, collaborative and system focused, a deliberate intent and commitment to a vision of what can be. The first step in the process is the brainstorming phase, working with others (educators, children, and families) to articulate what they want with regards values and character development. Framing the vision making process within a why-what-how-when-who framework may add depth to levels of buy-in, as well as to diverse ways of thinking about school wide character development practices. "It is not only important to ask how something is done. We must also ask why. It is in the why that we'll be able to move the world forward and secure a positive human future for all" (Association for Childhood Educational 
International, 2015). The how to change will be different for each school and will be the outcome of the why.

Additionally, principals can work with staff using the five questions of empowerment (Figure 2) to ascertain what their vision is for character development in their class/school, what they are currently doing, their knowledge and skill level in achieving this vision, what they are currently doing or need to be doing to attain these outcomes, and how satisfying this process is for themselves, students, and families.

\section{Principal as Coaching Teacher}

The principal as coaching teacher can break the vision making process down into explicit behaviors: What would we see ourselves doing and not doing if we were accountable, credible, communicable, non-coercive in our character development systems, practices, and process. An example of speaking respectfully is outlined in Table 2 and Table 3. Likewise, the principal could work with educators following an explicit framework of social behavior teaching (Figure 3, Carter, 2015).

Multi-level strategies, including the following, may influence this process: exploring relationships within schools and the resources within families; leading class meetings; planning cooperative learning experiences; demonstrations at school assemblies; probing child rearing practices (microsystem); conducting parent education classes within schools; student-led parent-teacher conferences; school newsletters and websites encouraging character building; school staff professional development (mesosystem); including character development into education districts protocols; government driven education campaigns at all levels of the community; traditional values community education programs; government, workplace and community sponsorship for school initiatives (exosystem); society-led multicultural mentoring and patron programs; government directives promoting cross cultural interactions will likely influence government policies supporting values education for all citizens; (macrosystem); mapping the degree of change or consistency over time with customs, laws, and values; studying the impact on traditional values of acculturation and assimilation over time (chronosystem). 
Principals as Patrons are supportive, virtuous, and protective of their Masters. They work with Masters expanding their professional and personal capacity in character development. This values based process entails building nurturing relationships, providing resources (budgetary, human, and technical), creating spaces for development, and sharing wisdom.

\section{Principal as Discerning Monitor}

Principals as discerning monitors would assess the level of knowledge, understanding and commitment to the shared vision/values mission of character building. They could observe, evaluate, and reflect on the efficiency and effectiveness of systems and for their alignment with the schools shared vision/mission. Articulating values based thinking principals respond to the developmental needs of their educators. Self-inventories could be formulated in an effort to encourage selfevaluation of a number of elements of schoolwide character building. Completed inventories could direct conversations around roles and responsibilities within and across microsystems, mesosystems and exosystems.

Aligning developmental stages (beginning, developing, and established) with commitment to the shared vision and the five questions of empowerment enables the principals to identify what supports, resources, and mentorship individual educators require. A needs analysis across environmental systems could inform the content of school wide character development initiatives could guard against piecemeal character development education. The planning cycle encompassing the microsystem and mesosystem may enable principals and educators to pursue the systematic enactment of character development experiences: determining learning goals across learning domains; selecting activities for implementation; developing activity plans; implementing plans; tracking learning goals; documenting learning; re-planning (MOE, 2013, pp. 20-21).

\section{Conclusion}

The exploratory study discussed in this article provides evidence of the importance of strategic authentic leadership in fostering character development within preschool spaces in CPS. Insights into character building in schools identified mission driven leaders making connections between and 
across different environmental systems. Practical processes are identified enabling allowing readers to convert learnings into their professional spaces. Our study's findings contribute to the literature on principals' character development practices across preschool spaces in Singapore.

\section{References}

Anderson, D. R. (2000). Character education: Who is responsible? Journal of Instructional Psychology, $27(3), 139$.

Association for Childhood Educational International. (March 30, 2015). Global news. Educating for the future. Retrieved from http:/ / acei.org/global-news/educating-for-the-future

Avolio, B. J., \& Gardner, W. L. (2005). Authentic leadership development: Getting to the root of positive forms of leadership. The Leadership Quarterly, 16(3), 315-338.

doi:10.1016/j.leaqua.2005.03.001

Avolio, B. J., Gardner, W. L., Walumbwa, F. O., Luthans, F., \& May, D. R. (2004). Unlocking the mask: A look at the process by which authentic leaders' impact follower attitudes and behaviors. The Leadership Quarterly, 15(6), 801-823. doi:10.1016/j.leaqua.2004.09.003

Banke, S., Maldonado, N., \& Lacey, C. (2012). Christian school leaders and spirituality. Journal of Research on Christian Education, 21(3), 235-264. doi:10.1080/10656219.2012.732806

Berkowitz, M. W. (2011). What works in values education? International Journal of Educational Research, 50(3), 153-158. doi:10.1016/j.ijer.2011.07.003

Berkowitz, M. W., \& Bier, M. C. (2005). What works in character education: A research-driven guide for educators? Washington, DC: Character Education Partnership. Retrieved August 25, 2015, from http://www.rucharacter.org/file/practitioners_518.pdf.

Berkowitz, M. W., \& Bier, M. C. (2007). What works in character education? Journal of Research in Character Education, 5(1), 29-48.

Braun, V., \& Clarke, V. (2006). Using thematic analysis in psychology. Qualitative Research in Psychology, 3(2), 77-101. doi:10.1191/1478088706qp063oa 
Brocki, J. M., \& Wearden, A. J. (2006). A critical evaluation of the use of interpretative phenomenological analysis (IPA) in health psychology. Psychology \& Health, 21(1), 87-108. doi:10.1080/14768320500230185

Bronfenbrenner, U., \& Morris, P. (2006). The bioecological model of human development. In W. Damon \& R. Lerner (Eds.), Handbook of child psychology: Vol 1. Theoretical models of human development (6th ed., pp. 793-828). Hoboken, NJ: Wiley.

Carter, M. (2015). Social rules according to young children. Australasian Journal of Early Childhood, $41(2), 32-40$.

Carter, M., \& Dasson, M. (2014). What is not okay is not okay. Are preschool educators about controlling children or are they about teaching and learning? Early Educators, 24, 3-11.

Carter, M., \& Ellis, C. (2016). Work “with" me. Learning prosocial behaviours Unpublished Manuscript Australasian Journal of Early Childhood

Carter, M., Dasson, M., \& Kanakis, K. (2016). It is not about “being best in the world." It is about "being best for the world." In M. S. Khine (Ed.), Non-cognitive factors and educational attainment (pp. 355-372). Rotterdam, The Netherlands: Sense Publishers.

Carter, M., \& Frewin, A., \& Chunn, J. (2014). Through the eyes of parents: A Singaporean perspective of the importance of cognitive and non-cognitive skills for six year old children. Australasian Journal of Early Childhood, 39(3), 57-65.

Character.org. (2014). The eleven principles of effective character education. A guide for schools and districts. Washington, DC: Author. Retrieved from http://www.character.org/uploads/PDFs/ElevenPrinciples_new2010.pdf

Erford, B. (2015). Research and evaluation in counseling. Stamford, CT: Cengage Learning.

Gardner, W. L., Avolio, B. J., Luthans, F., May, D. R., \& Walumbwa, F. (2005). “Can you see the real me?" A self-based model of authentic leader and follower development. The Leadership Quarterly, 16(3), 343-372. doi:10.1016/j.leaqua.2005.03.003

Gordon, M., \& Green, J. (2008). 34 roots of empathy: Changing the world, child by child. Education Canada, 48(2), 34-36.

Henderson, D., \& Thompson, C. (2011). Counseling children. Stamford, CT: Cengage Learning. 
Hester, J. (1995). Bridges. Building relationships and resolving conflicts. Chapel Hill, NC: New View.

Hill, I. (2014). Internationally minded schools as cultural artefacts: Implications for school leadership. Journal of Research in International Education, 13(3), 175-189. doi:10.1177/1475240914556199

Leithwood, K. (2010). Characteristics of school districts that are exceptionally effective in closing the achievement gap. Leadership and Policy in Schools, 9(3), 245-291. doi:10.1080/15700761003731500

Lewis, S., Hays, B., \& Robinson, E. (2011). Implementing an authentic character education curriculum. Childhood Education, 87(4), 227-231. doi:10.1080/00094056.2011.10523183

Lickona, T. (1996). Eleven principles of effective character education. Journal of Moral Education, 25(1), 93-100. doi:10.1080/0305724960250110

Lickona, T., Schaps, E., Lewis, C. (2007). CEP's eleven principles of effective character education. Character Education Partnership. Available from http://www.character.org/elevenprinciples

Keat, H. W. (2011, September). Opening address, Minister for Education. Presented at the Ministry of Education (MOE) Work Plan Seminar, Ngee Ann Polytechnic Convention Centre, Singapore. Retrieved from http://www.moe.gov.sg/media/speeches/2011/09/22/work-plan-seminar2011.php

Kohn, A. (1996). Beyond discipline: From compliance to community. Alexandria, VA: ASCD.

May, D. R., Chan, A. Y. L., Hodges, T. D., \& Avolio, B. J. (2003). Developing the moral component of authentic leadership. Organizational Dynamics, 32(3), 247-260. doi:10.1016/S0090-2616(03)00032-9

Minckler, C. H. (2014). School leadership that builds teacher social capital. Educational Management Administration \& Leadership, 42(5), 657-679. doi:10.1177/1741143213510502

Ministry of Education, Singapore. (2012a). 2014 syllabus character and citizenship education primary. Singapore: Ministry of Education, Student Development Curriculum Division. Retrieved from http://www.moe.gov.sg/education/syllabuses/character-citizenship-education/files/2014character-citizenship-education-eng.pdf

Ministry of Education, Singapore. (2012b). Nurturing early learners: A curriculum framework for kindergartens (revised 2012) guide for parents. Singapore: Ministry of Education, Student Development Curriculum Division. Retrieved from 
http://www.moe.gov.sg/education/preschool/files/kindergarten-curriculum-frameworkguide-for-parents.pdf

Ministry of Education. (2013). Nurturing early learners: A curriculum framework for kindergartens in Singapore. Educators' guide: Overview. Singapore: Ministry of Education. Retrieved from http://www.moe.gov.sg/education/preschool/files/nel-edu-guide-overview.pdf

McArdle, W. J. (2002). A Mindfields manual of behaviour. Brisbane, Australia: PEOMO Productions.

McArdle, W. J., \& Carter, M. (2009). A Mindfields manual for the helping profession. The art and science of authentic helpfulness. Brisbane, Australia: PEOMO Productions.

Papalia, D., \& Martorell, G. (2015). Experience human development (13th ed.). New York, NY: McGraw Hill Education.

Rosa, E. M., \& Tudge, J. (2013). Urie Bronfenbrenner's theory of human development: Its evolution from ecology to bioecology. Journal of Family Theory \& Review, 5(4), 243-258. doi:10.1111/jftr.12022

Sim, J. B., \& Low, E. L. (2012). Character and citizenship education: Conversations between personal and societal values. Asia Pacific Journal of Education, 32(4), 381-394. doi:10.1080/02188791.2012.746214

Shamir, B., \& Eilam, G. (2005). “What's your story?” A life-stories approach to authentic leadership development. The Leadership Quarterly, 16(3), 395-417. doi:10.1016/j.leaqua.2005.03.005

Sojourner, R. (2014). It's unanimous: Effective character education is not quick or superficial, and it begins with caring relationships. Journal of Character Education, 10(1), 69-75.

Solvason, C. (2005). Investigating specialist school ethos or do you mean culture? Educational Studies, 31(1), 85-94. doi:10.1080/0305569042000310985

Toh, K., Chia, Y., \& Lua, J. (2012, August 28). Without extra lessons, our kids may lose out. The Straits Times, A7.

Wilhelm, G., \& Firmin, M. (2008). Character education: Christian education perspectives. Journal of Research on Christian Education, 17(2), 182-198. doi:10.1080/10656210802433384

Yearbook of Statistics, Singapore. (2015). Retrieved from

http://www.singstat.gov.sg/publications/publications-and-papers/reference/yearbook-ofstatistics-singapore 
Zhu, W., Riggio, R. E., Avolio, B. J., \& Sosik, J. J. (2011). The effect of leadership on follower moral identity: Does transformational/transactional style make a difference? Journal of Leadership $\mathcal{E}$ Organizational Studies, 18(2), 150-163. doi:10.1177/1548051810396714 


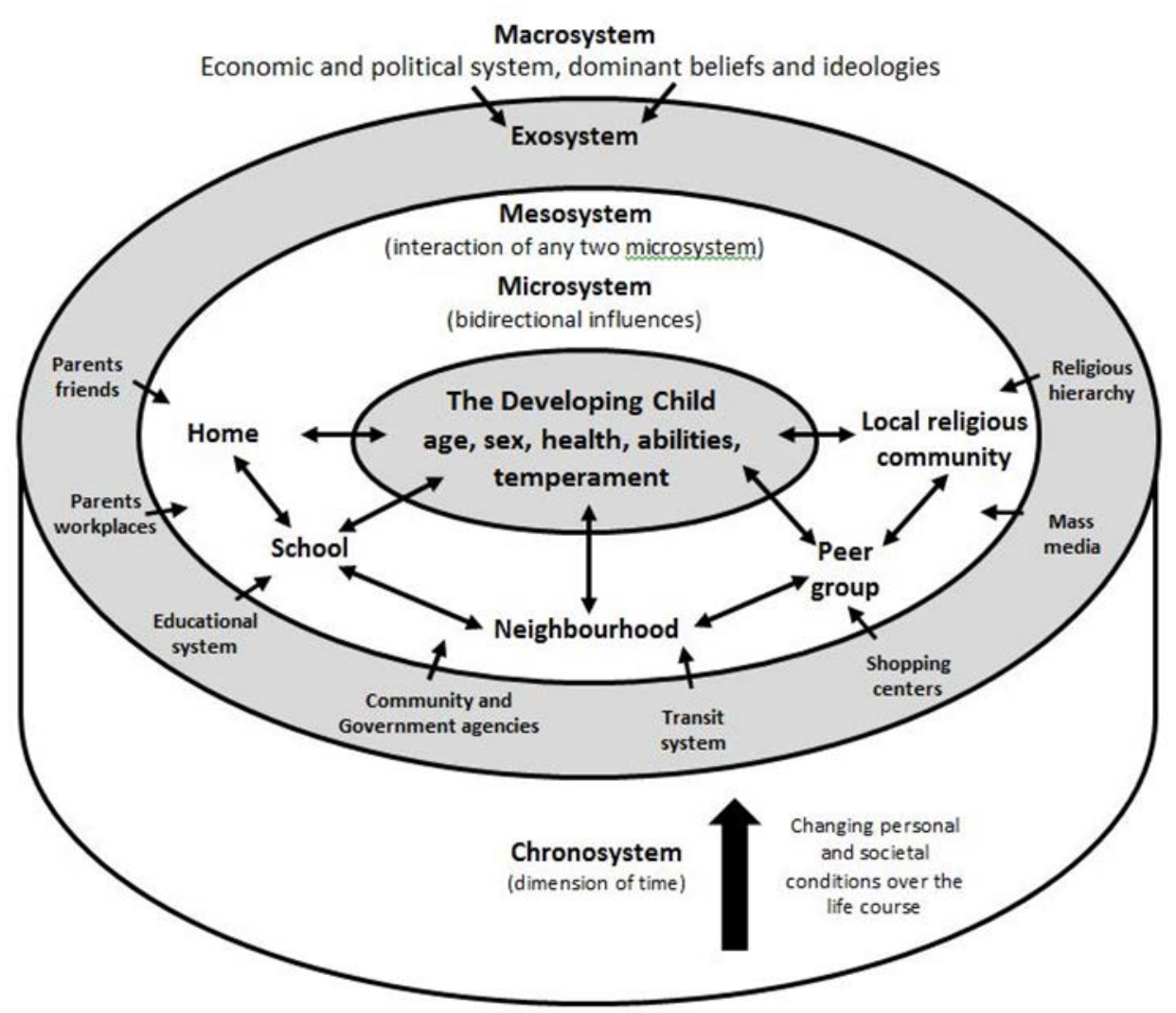

Figure 1. Urie Bronfenbrenner's Bioecological Model of Development Reprinted from Experience Human Development (13 ${ }^{\text {th }}$ ed.). (p. 33), by Papalia, D., \& Martorell, G. 2015, New York, McGraw Hill Education@ 
Five Questions of Empowerment

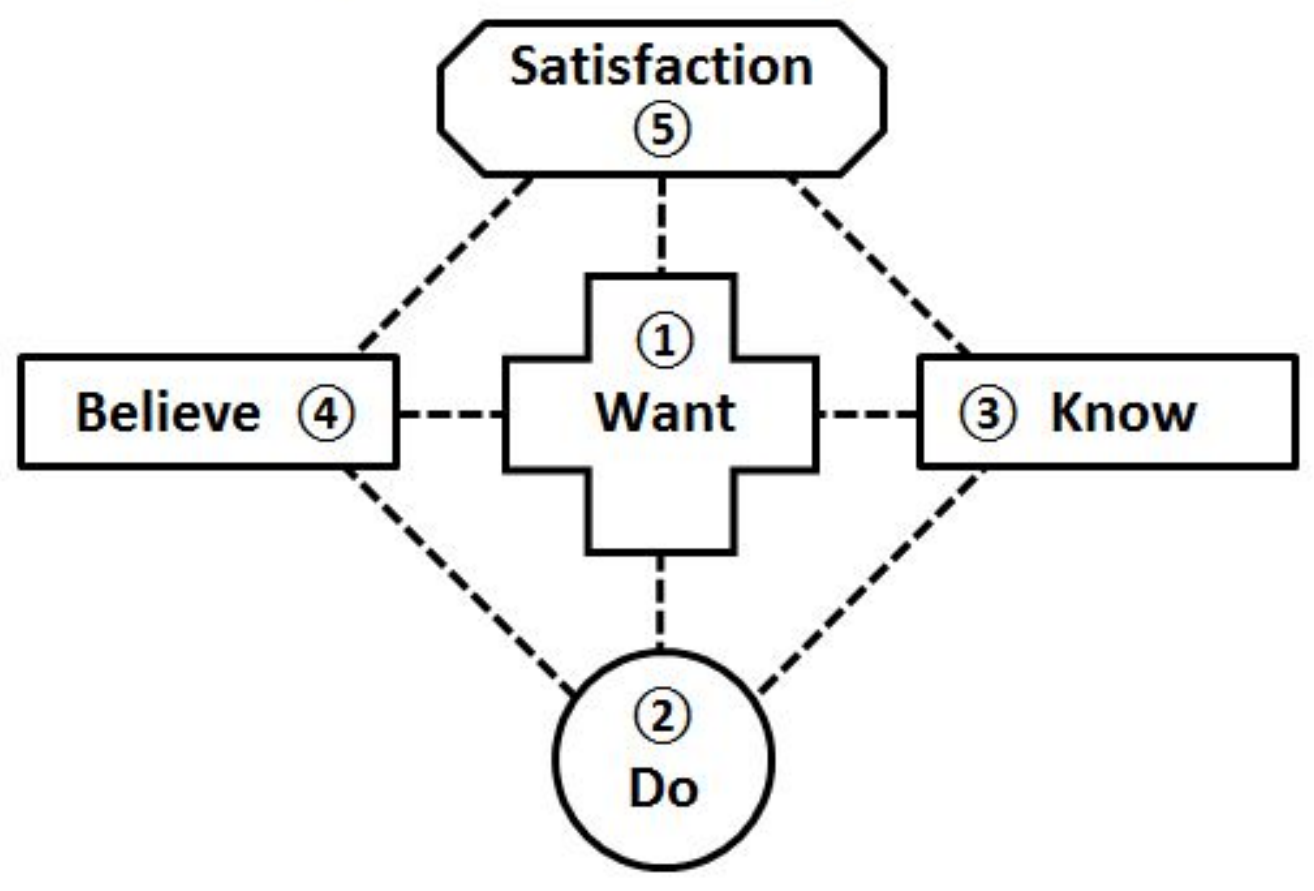

Figure 2: Five Questions of Empowerment (McArdle, 2002; McArdle \& Carter, 2009) 
Phase 7

Teaching and implementing the social consequence system aligned with the social behaviours

Phase 6

Re-teaching and re-practicing social behaviours. Monitoring growth, development and success

Phase 5

Scaffolding children's learning within their zone of proximal development

Phase 4

Intentionally practicing social behaviours across spaces.

Providing on the spot guidance and behaviour specific feedback

Phase 3

Demonstrating, modelling and role playing social behaviours.

Planning for skill generalisation across different learning and teaching spaces

Phase 2

Describing, explaining and discussing the purpose for and meaning of the social behaviours

\section{Phase 1}

Identifying and defining baseline social behaviours (social rules)

Figure 3: Behaviour Teaching Process 
Table 1

\section{Effective Principles of Character Education}

1. The principal promotes core values as the foundation of good character. These includes the values of respect, compassion, appreciation, patience, inclusion, trust and cooperation. (Shared Vision/Values Alignment)

2. “Character” include four component parts: thinking, doing, feeling and some physiological reaction, such as a rapid heartbeat. (Empowerment)

3. The principal endorses a comprehensive, intentional, and proactive approach to character development. This results in a sense of purpose with clear expectations. (Shared Vision/Values Alignment)

4. The principal promotes a thoughtful and compassionate school community. (Shared Vision/Values Alignment)

5. $\quad$ The principal provides educators, students and families with opportunities for moral action. (Empowerment)

6. The principal offers a curriculum that respects all learners, develops their character, and sets them up for succeed. (Shared Vision/Values Alignment)

7. The principal strives to foster educators' and students' self-motivation, building a sense of competence. (Empowerment)

8. The principal leads an ethical learning community sharing responsibility for character education, following the same core values that guide the education of students. (Shared Vision/Values Alignment)

9. The principal fosters shared leadership and is supportive of the character education initiatives. (Empowerment; Shared Vision/Values Alignment)

10. The principal engages families and community members as partners in the characterbuilding effort. (Shared Vision/Values Alignment) 
11. Consistently the principal monitors and evaluates the school's culture, the functioning of its staff as character educators, and the extent to which educators and students manifest good character.

Reference: Adapted from Character.org (2014), pp. 2 - 23 
Table 2

Speaking Respectfully

\begin{tabular}{|l|l|}
\hline $\begin{array}{l}\text { Speaking Respectfully: Doing } \\
\text { Looks like / Sounds like }\end{array}$ & $\begin{array}{l}\text { Speaking Respectfully: Not Doing } \\
\text { Looks like / Sounds like }\end{array}$ \\
\hline Talking & Screaming \\
\hline Polite language & Rude language \\
\hline Compliments & Put downs \\
\hline Non-Blame talk & Blame talk \\
\hline Calm tome & Aggressive tone \\
\hline Nodding & Interrupting \\
\hline Focusing & Ignoring \\
\hline Listening to understand & Listening to be understood \\
\hline Taking turns to talk & Talking over others \\
\hline Open body language & Closed body language \\
\hline
\end{tabular}


Table 3

Respectful-Disrespectful Language

\begin{tabular}{|l|l|}
\hline \multicolumn{1}{|c|}{ Disrespectful Language } & \multicolumn{1}{c|}{ Respectful Language } \\
\hline You are pathetic & $\begin{array}{l}\text { You need to focus and continue } \\
\text { working. }\end{array}$ \\
\hline You are horrible & $\begin{array}{l}\text { You are very active, but you need to } \\
\text { remember to follow our rules. }\end{array}$ \\
\hline You are an idiot & You are still learning. Keep trying. \\
\hline You are stupid & $\begin{array}{l}\text { Even though it is hard, it is good to have } \\
\text { a go. }\end{array}$ \\
\hline
\end{tabular}

